\title{
Analysis of Quantum-well Heterojunction Emitter Bipolar Transistor Design
}

\author{
Hsu Myat Tin Swe ${ }^{1,2}$, Hla Myo Tun ${ }^{1}$, Maung Maung Latt ${ }^{2}$ \\ ${ }^{1}$ Department of Electronic Engineering, Yangon Technological University, Yangon, Myanmar \\ ${ }^{2}$ Department of Electronic Engineering, Technological University (Taungoo), Taungoo, Myanmar
}

Email address:

hlamyotun.ytu@gmail.com (H. M. Tun)

\section{To cite this article:}

Hsu Myat Tin Swe, Hla Myo Tun, Maung Maung Latt. Analysis of Quantum-Well Heterojunction Emitter Bipolar Transistor Design. American Journal of Nano Research and Applications. Vol. 9, No. 1, 2020, pp. 9-15. doi: 10.11648/j.nano.20200801.12

Received: March 16, 2020; Accepted: April 1, 2020; Published: April 13, 2020

\begin{abstract}
The paper presents the analysis of Quantum-well Heterojunction Emitted Bipolar Transistor Design based on physical parameters with numerical computations. The specific objective of this work is to enhance the physical performance of the Quantum-well Heterojunction Emitted Bipolar Transistor Design in real world applications. There have been considered on the III-V compound materials like GaAs for p-type layer, AlGaAs for n-type layer and InGaAs for quantum-well layer for different kinds of junctions which were developed in HEBT structure. In this analyses, the parameters for implemented HEBT structure were evaluated to find the multi-quantum-well band diagram, operating frequency (unity beta frequency), rise time, storage delay time, fall time, minority carrier distribution, current gain variation, voltage-current characteristics and phonon control on quantum-well device. In these analyses, the physical parameters were carried out based on the experimental studies from the recent research works and many literatures. The physical parameters which used in this HEBT structure have been provided to solve the real fabrication problems by using theoretical concepts. The quantum-well device based on III-V compound materials was performed by using numerical techniques with the help of MATLAB. The simulation results confirm that the developed HEBT structure was suitable for fabricating the real devices for high performance applications.
\end{abstract}

Keywords: Quantum-well Structure, III-V Compound, Heterojunction Emitter Bipolar Transistor, Semiconductor Device Fabrication, Numerical Analysis, MATLAB

\section{Introduction}

The Heterojunction bipolar transistors (HBTs) have been widely considered for many decades [1-3]. It is known that the energy discontinuity $\Delta \mathrm{E}_{\mathrm{v}}$ in the valence band of emitter-base heterojunctions can efficiently block the back injection of hole currents and leads to a high current gain. Therefore, the large band discontinuity $\Delta \mathrm{Ev}$ improves the thermal stability, and this enables, for example, the high-temperature operation of InGaP/GaAs HBTs with current gains which are only reduced slightly at an elevated temperature [4]. With the embeddedness of a quantum well (QW) into the base region, the light-emitting transistor (LET), which is not only a QW-HBT but also a novel high-speed light source with three-port inputs for optical communication, was demonstrated in 2004 [5]. Due to the reduced valence band discontinuity $\triangle \mathrm{EV}$ between the emitter and the base and raised thermal energy at an elevated temperature, the current gain of typical HBTs is usually a decreasing function of the operation temperature. The QW-HBT, on the other hand, exhibits a totally different trend to that of a typical HBT [7-14].

First, modeling of a commercially available HBT was performed to provide a starting point that could be modified into the novel structure. This first model was adjusted so that the modeled results were a close match to the measured results of the manufactured device. This HBT has an emitter region composed of highly n-type doped cap layers of AlGaAs at the emitter contact followed by a region of n-type GaAs and then a region of n-type AlGaAs. The base consists of $1019 \mathrm{~cm}-3$ p-type doped GaAs of a thickness of $1000 \mathrm{~A}^{\circ}$. The collector is composed of n-type AlGaAs. The quantum well base heterojunction bipolar transistor (QWBHBT) was designed by modifying the model of the commercially available HBT. The major modification was the creation of a quantum well in the base of the structure by creating a double heterojuction with InGaAs. The base material is still composed of $1018 \mathrm{~cm}-3$ 
p-type doped GaAs, but the thickness of this region is reduced to $240 \mathrm{~A}^{\circ}$ so that it is comparable to the wavelength of the electrons passing through it. The AlGaAs region in the emitter, adjacent to the base, remains. An additional AlGaAs region in the collector adjacent to the base was added. The thickness of both $\mathrm{AlGaAs}$ regions is $400 \mathrm{~A}^{\circ}$ and both regions are n-type doped. The combination of the lower energy gap p-type GaAs region sandwiched between two higher energy gap n-type AlGaAs regions creates a double heterojunction that results in the formation of a deep quantum well for the holes injected into the base from the base contact and a quantum barrier for the electrons injected from the emitter through the base into the collector. The remaining structure remains the same as in the commercial device.

In view of these, we develop a modified charge-control model to describe the temperature-dependent electrical characteristics of QW-HBTs. The thermionic emission is adopted to model the escape rate of electrons out of the QW, which influences both the minority carrier distribution in the base and current gain. The temperature dependencies of diffusion, capture, and escape processes of electrons in the heavily p-doped base are incorporated into the modified charge-control model of QW-HBTs. Among these factors, the faster escape of electrons out of the QW at the higher temperature is shown to be the main cause to the unusual temperature-dependent current gain of QW-HBTs.

The research work was formulated based on the theoretical idea from the research laboratories of Semiconductor Electronics Fabrication. The fundamental concept of the Quantum-Well structure for Bipolar Transistor design was very novel in advanced technology development. The scope of this research covers the four main contributions. The first contribution is focused on the design of III-V Compound-based Quantum-Well Transistor structure with numerical parameters. The second contribution is emphasized on multi-Quantum-Well layers for target transistor design. The third contribution is completed the estimation of physical parameters for designed transistor. The last contribution is targeted on the measurement process for developed HEBTs design.

The rest of the paper is organized as follows. Section II presents the targeted quantum-well HEBT structure based on different semiconductor materials for different layers. Section III mentions the governing equations for numerical analysis. Section IV was pointed out the implementation of the numerical analysis. Section V expresses the results and discussions. Section VI concludes the completion of the research works.

\section{Targeted Quantum-Well HEBT Structure}

Most of Single Junction Semiconductor Devices were formulated as simple heterojuction structure for observing the confinement of electron in the junction. For two junctions Semiconductor Devices like Heterojunction Emitter Bipolar
Transistors (HEBTs), the Quantum-Well layers are challenging issues to acquire the better performance results on switching and amplification. The III-V compound-based Quantum Well Transistor Design (n- $\mathrm{Al}_{0.3} \mathrm{Ga}_{0.7} \mathrm{As} / \mathrm{p}-\mathrm{GaAs} / \mathrm{i}-\mathrm{In}_{\mathrm{x}} \mathrm{Ga}_{1-\mathrm{x}} \mathrm{As} / \mathrm{p}-\mathrm{GaAs} / \mathrm{n}-\mathrm{Al}_{0.3} \mathrm{Ga}_{0.7} \mathrm{As}$ ) is an idea to solve the high performance applications in Semiconductor Electronics areas.

The Quantum-Well structure for HEBTs device modeling with mathematical analysis has to be designed. (MBE is the technique for fabrication by experimental studies). The Band Diagram for Quantum Well Transistor device has to be analyzed. The carrier dynamics and transport in the Quantum Well layer of HEBT has to be evaluated. The physical properties of HEBT device (Electrical, Vibration) has to be measured.

In order to solve the real problem to design the quantum-well HEBT structure, the proposed quantum-well HEBT structure is shown in Figure 1.

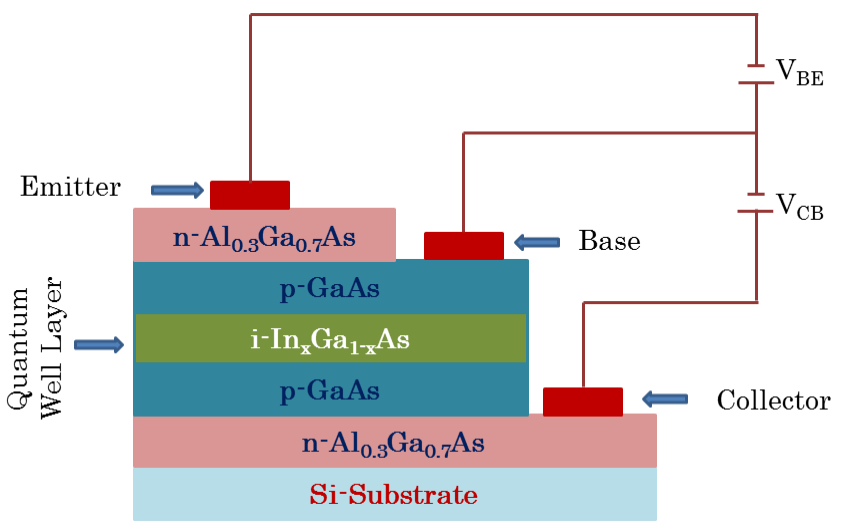

Figure 1. Proposed Quantum-Well HEBT Structure [15].

\section{Governing Equations}

The governing equations for designing the quantum-well HEBT structure were very important parameters for device fabrications.

\subsection{Base Current in Shallow Emitters}

If the emitter is very thin, the hole distribution in the emitter approaches a linear distribution, as illustrated in Figure 1. This occurs because there is little or no recombination in the bulk of the emitter when the emitter is thin, i.e. when the emitter depth WE is much smaller than the hole diffusion length in the emitter. All holes injected from the base into the emitter recombine at the emitter contact, pinning the hole concentration at the contact to the equilibrium value i.e. pe 0 . At the edge of the emitter/base depletion region, the hole concentration is determined by the bias across the emitter/base

$$
\text { junction. } \mathrm{p}_{\mathrm{e}}(0)=\mathrm{p}_{\mathrm{e} 0} \exp \frac{\mathrm{qV} \mathrm{BE}_{\mathrm{BE}}}{\mathrm{kT}}
$$

In the case where all the applied voltage is dropped across the depletion region the base current is entirely diffusion current. Current Density Equation can then be written as: 


$$
\mathrm{J}_{\mathrm{p}}=-\mathrm{qD} \mathrm{D}_{\mathrm{pe}}\left(\text { gradient of } \mathrm{p}_{\mathrm{e}}\right)
$$

The gradient of the hole distribution can be calculated from this equation.

$$
\begin{gathered}
\text { gradient }=\frac{d p_{e}}{d x}=-\frac{p_{e 0} \exp \frac{q V_{B E}}{k T}-p_{e 0}}{W_{E}} \\
\therefore J_{p}=-q D_{p e} \frac{d p_{e}}{d x}=\frac{\mathrm{qD}_{p e} p_{e 0} 0}{W_{E}}\left(\exp \frac{q V_{B E}}{k T}-1\right)
\end{gathered}
$$

A more useful form of this equation can be obtained by using:

$$
\begin{gathered}
\mathrm{p}_{\mathrm{e} 0} \mathrm{n}_{\mathrm{e} 0}=\mathrm{n}_{\mathrm{i}}^{2} \\
\mathrm{p}_{\mathrm{e} 0} \mathrm{~N}_{\mathrm{de}}=\mathrm{n}_{\mathrm{i}}^{2} \\
\mathrm{p}_{\mathrm{e} 0}=\frac{\mathrm{n}_{\mathrm{i}}^{2}}{\mathrm{~N}_{\mathrm{de}}}
\end{gathered}
$$

Substituting equation (4) into equation (3) gives:

$$
\mathrm{I}_{\mathrm{B}}=\frac{\mathrm{qAD} \mathrm{pe}_{\mathrm{pe}}^{2}}{\mathrm{~W}_{\mathrm{E}} \mathrm{N}_{\mathrm{de}}} \exp \frac{\mathrm{qV} \mathrm{V}_{\mathrm{BE}}}{\mathrm{kT}}
$$

where it has been assumed that $\mathrm{V}_{\mathrm{BE}}>>\mathrm{kT} / \mathrm{q}\left(\mathrm{V}_{\mathrm{BE}}>>25 \mathrm{mV}\right.$ at room temperature). Equation (5) gives some useful insight into transistor design options, since it shows that the base current for a shallow emitter is inversely proportional to the product of the emitter depth WE and the emitter doping $\mathrm{N}_{\text {de }}$.

\subsection{Collector Current}

In high-speed bipolar transistors, the basewidth needs to be as small as possible (typically less than $0.1 \mu \mathrm{m}$ ) so that electrons can rapidly traverse the base. The typical practical basewidth of less than $0.1 \mu \mathrm{m}$ compares with a typical electron diffusion length in the base of $10 \mu \mathrm{m}$. It is clear that in this case WB $<<$ Lnb and hence that the electron distribution in the base must be linear.

The electron concentration at the edge of the emitter/base depletion region is given by an equation analogous to equation (1):

$$
\mathrm{n}_{\mathrm{b}}(0)=\mathrm{n}_{\mathrm{b} 0} \exp \frac{\mathrm{qV} \mathrm{VE}_{\mathrm{BE}}}{\mathrm{kT}}
$$

The electron concentration at the edge of the collector/base depletion region is given by:

$$
\mathrm{n}_{\mathrm{b}}\left(\mathrm{W}_{\mathrm{B}}\right)=\mathrm{n}_{\mathrm{b} 0} \exp -\frac{\mathrm{qV}_{\mathrm{BE}}}{\mathrm{kT}} \approx 0
$$

For practical values of collector/base reverse bias the electron concentration at the edge of the collector/base depletion region is close to zero. For a linear electron distribution across the base, the diffusion equation can then be written as:

$$
\mathrm{J}_{\mathrm{n}}=\mathrm{qD}_{\mathrm{nb}}\left(\text { gradient of } \mathrm{n}_{\mathrm{b}}\right)=\mathrm{qD}_{\mathrm{nb}}\left(\frac{\mathrm{n}_{\mathrm{b} 0} \exp \frac{\mathrm{q} \mathrm{v}_{\mathrm{BE}}}{\mathrm{kT}}}{\mathrm{w}_{\mathrm{B}}}\right)
$$

$$
\mathrm{J}_{\mathrm{n}}=\frac{\mathrm{qD}_{\mathrm{nb}} \mathrm{n}_{\mathrm{b} 0}}{\mathrm{~W}_{\mathrm{B}}} \exp \frac{\mathrm{qV}_{\mathrm{BE}}}{\mathrm{kT}}
$$

A more useful form of this equation can be obtained by using:

$$
\begin{gathered}
\mathrm{p}_{\mathrm{b} 0} \mathrm{n}_{\mathrm{b} 0}=\mathrm{n}_{\mathrm{i}}^{2} \\
\mathrm{~N}_{\mathrm{ab}} \mathrm{n}_{\mathrm{b} 0}=\mathrm{n}_{\mathrm{i}}^{2} \\
\mathrm{n}_{\mathrm{b} 0}=\frac{\mathrm{n}_{\mathrm{i}}^{2}}{\mathrm{~N}_{\mathrm{ab}}}
\end{gathered}
$$

Substituting equation (10) into equation (9) gives:

$$
\mathrm{I}_{\mathrm{C}}=\frac{\mathrm{qAD}_{\mathrm{nb}} n_{\mathrm{i}}^{2}}{\mathrm{~W}_{\mathrm{B}} \mathrm{N}_{\mathrm{ab}}} \exp \frac{\mathrm{qV}_{\mathrm{BE}}}{\mathrm{kT}}
$$

This equation gives some useful insight into transistor design options, since it shows that the collector current for a shallow emitter is inversely proportional to the product of the basewidth $\mathrm{W}_{\mathrm{B}}$ and the base doping $\mathrm{N}_{\mathrm{ab}}$.

\section{Implementation}

The Quantum-Well Heterojunction Bipolar Emitter Transistor (HEBT) is a vital role to enhance the hybrid system of Quantum-Well structure and Heterojunction Bipolar Emitter Transistor structure. The development of new technology for semiconductor electronics advancement for future technology is very important for device fabrications and measurement techniques in real world applications. The block diagram for the implementation programme for successful research works are shown in Figure 2.

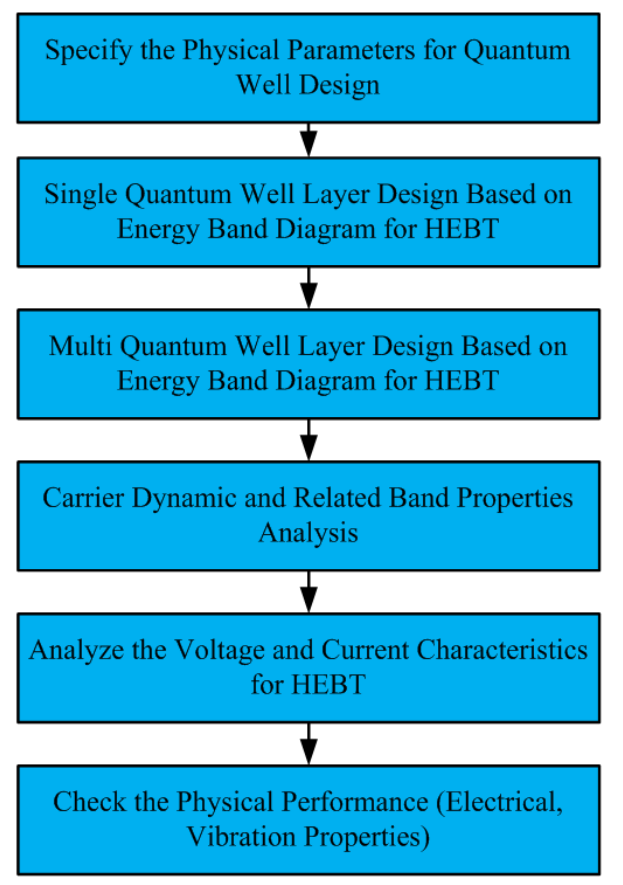

Figure 2. Block Diagram of Implementation Programme.

There are five main steps for the implementation. The physical parameters for Quantum-Well Design have to be 
specified for the implementation. After that, the analysis on single Quantum-Well Layer Design based on Energy Band Diagram Design for HEBT was completed. The multi-Quantum-Well layer for consideration of Energy Band Diagram Design for HEBT was calculated. The carrier dynamics and related band properties analyses have been done based on the developed HEBT structure. After that, the Voltage and Current Characteristics for HEBT has to be evaluated. Finally, the electrical characteristics and vibration characteristics for developed HEBT have to be calculated. That is the measurement process for confirmation of the high performance condition of the designed HEBT structure for several applications and fabrication processes. According to the numerical analyses on the development of Quantum-Well Heterojunction Bipolar Emitter Transistor (HEBT), the details implementations on the model of semiconductor devices have been obtained the high performance condition of the transistor design.

The step by step procedures for implementation processes could be completed based on the physical properties references from the experimental studies of recent works. It is very important to complete this methodologies for solving the research problems from the experimental points of view.

\section{Results and Discussions}

The single quantum-well structure was analyzed in [16] and it has some limitation for designing the high performance HEBT design in real world applications. The multi quantum-well design may be suitable for high performance HEBT structure for high frequency applications. The quantum-well layers are very important to design the high frequency condition and it was developed by using MATLAB. Figure 3 demonstrates the Multi Quantum-Well Design for HEBT for real applications.

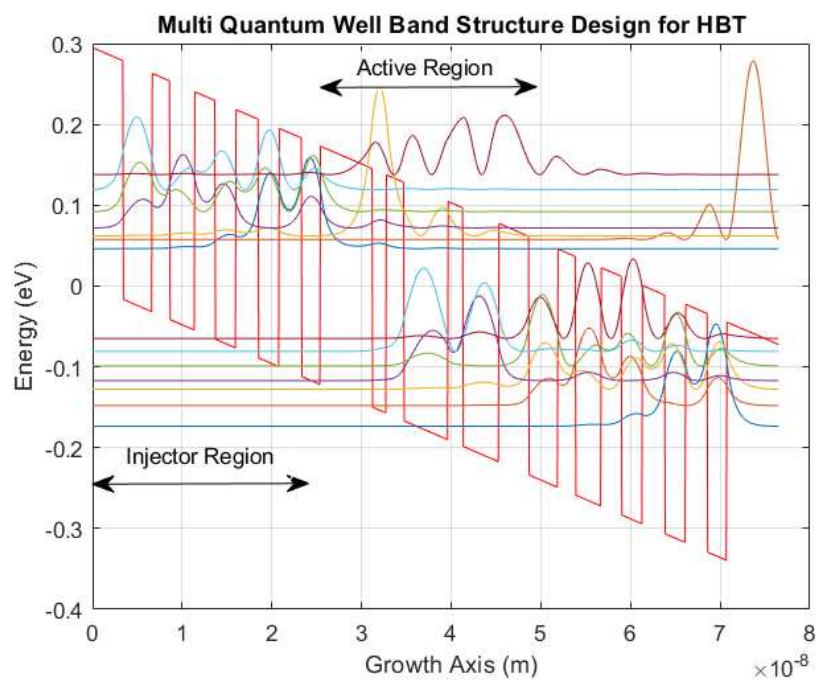

Figure 3. Multi Quantum-Well Design for HEBT [16].

The factor of $\mathrm{W} / \mathrm{LB}$ is from 0.1 to 10 for $\mathrm{VCB}=0$ condition is shown in Figure 4. If the factor is lower and lower, the minority distribution might be linear.

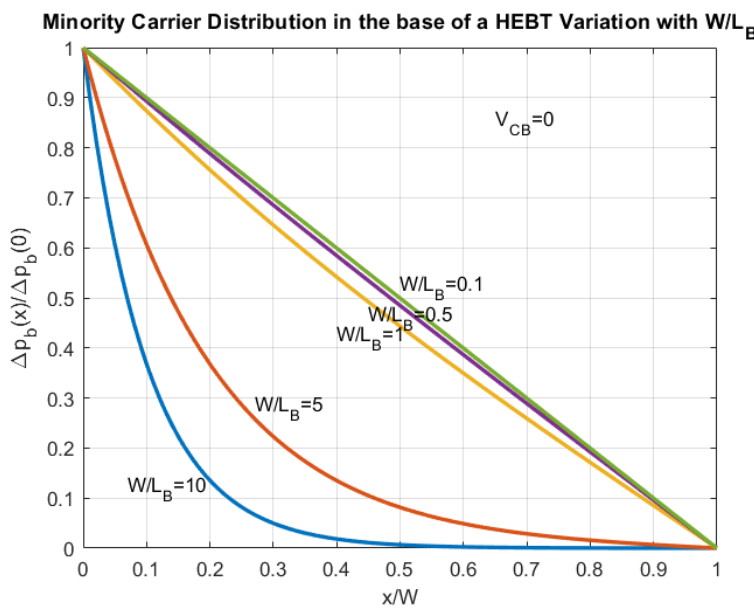

Figure 4. Minority Carrier Distribution in Base of a HEBT variation with $W / L_{B}$ [16].

The three regions for HEBT could be observed. The active region is started from the highest minority distribution to lowest level. The cut off region is always constant level below the zero distribution line. The saturation region is gradually decreased from the highest level to approximately two-third level of distribution.
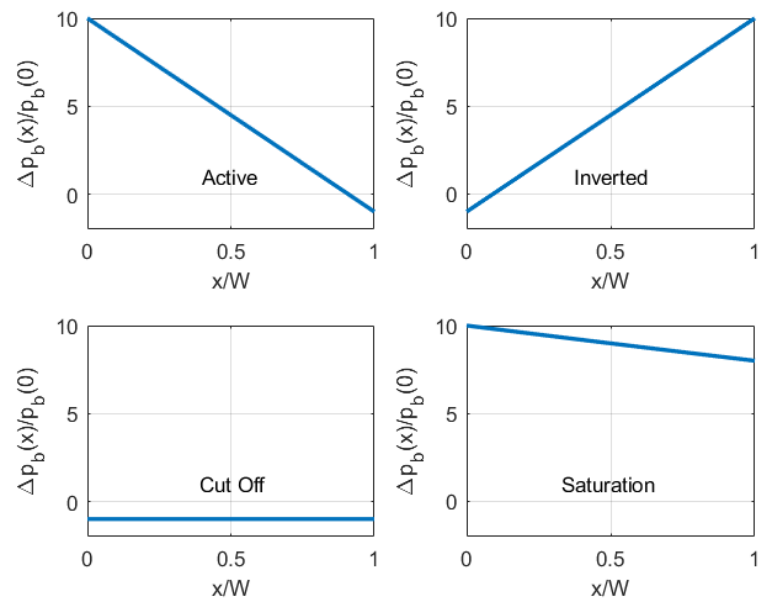

Figure 5. HEBT Biasing Mode Illustration. [16]

The four ratios of $\mathrm{N}_{\mathrm{E}} / \mathrm{N}_{\mathrm{E} 0}, \mathrm{~N}_{\mathrm{B}} / \mathrm{N}_{\mathrm{B} 0}, \tau_{\mathrm{E}} / \tau_{\mathrm{E} 0}$ and $\tau_{\mathrm{B}} / \tau_{\mathrm{B} 0}$ is mentioned in Figure 6. The calculation results on $\beta$ w.r.t $\mathrm{N}_{\mathrm{E}} / \mathrm{N}_{\mathrm{E} 0}$ is changing from $8 \times 10^{-3}$ to $3 \times 10^{-3}$. The calculation results on $\beta$ w.r.t $\mathrm{N}_{\mathrm{B}} / \mathrm{N}_{\mathrm{B} 0}$ is changing from $1 \times 10^{-3}$ to $1 \times 10^{-1}$. The calculation results on $\beta$ w.r.t $\tau_{\mathrm{E}} / \tau_{\mathrm{E} 0}$ are changing from 100 to 500 . The calculation results on $\beta$ w.r.t $\tau_{\mathrm{B}} / \tau_{\mathrm{B} 0}$ are changing from $1 \times 10^{-1}$ to $1 \times 10^{-3}$.

The actual results of $I_{C}$ and $I_{B}$ are very close to ideal values of $\mathrm{I}_{\mathrm{C}}$ and $\mathrm{I}_{\mathrm{B}}$ based on the values change of $\mathrm{V}_{\mathrm{EB}}$ from 0.3 to 0.8 volts for numerical analysis which was shown in Figure 7.

The changes of $\beta$ values are started from $1 \times 10^{-9}$ to $1 \times 10^{-1}$ with between 50 and 300 in real condition which was shown in Figure 8 . 

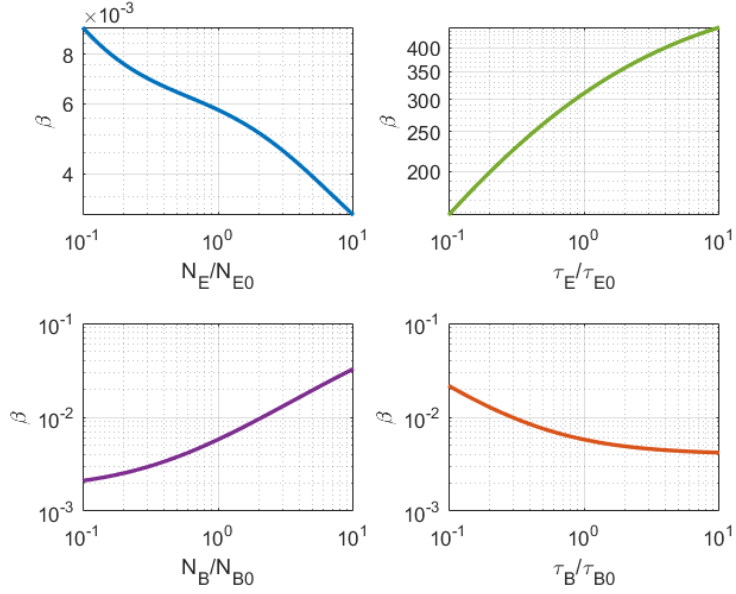

Figure 6. $\beta$ Calculation. [16].

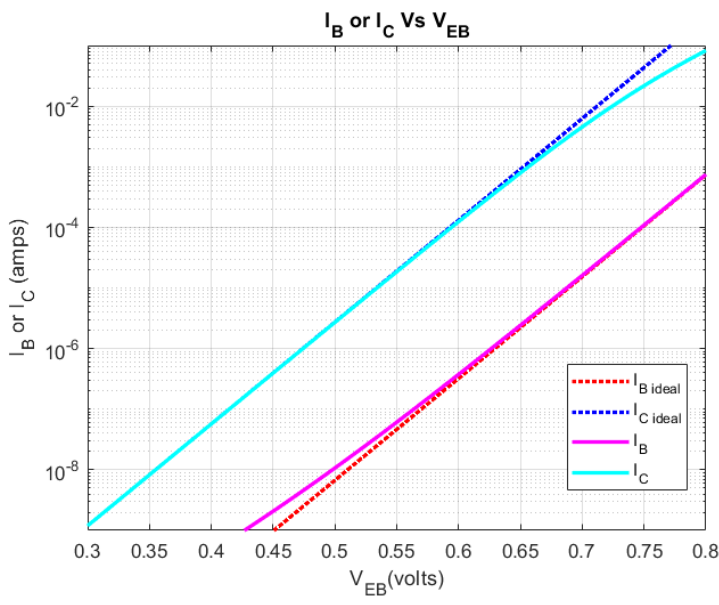

Figure 7. $I_{B}$ or $I_{C} V S V_{E B}$. [16].

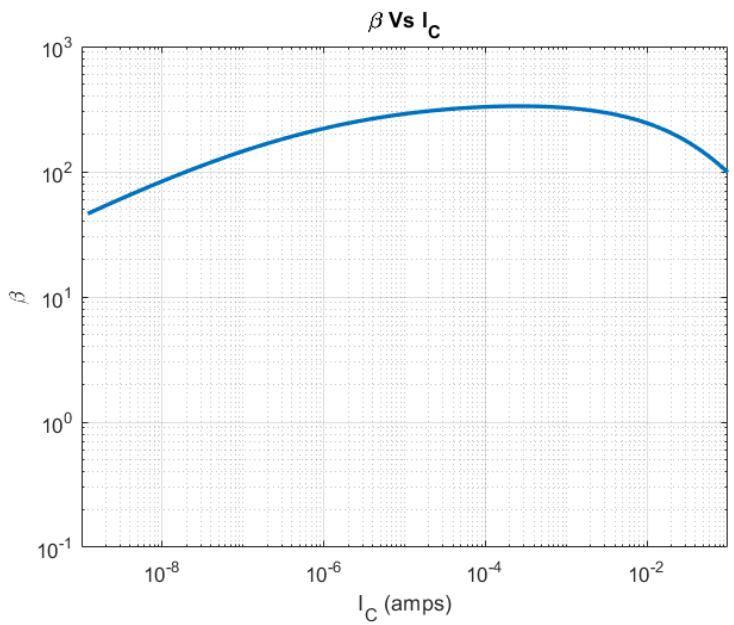

Figure 8. $\beta$ VS $I_{C}$. [16]

Figure 9 illustrates the Current Gain Vs Unity Beta Frequency. The changes of frequency effects on the current gain of the developed quantum-well HEBT design could be observed in this picture. The values of current gain gradually change from 200 to 0.03 from $1 \mathrm{MHz}$ to $1 \mathrm{GHz}$ frequency ranges. It depends on the materials properties for designing the HEBT structure.

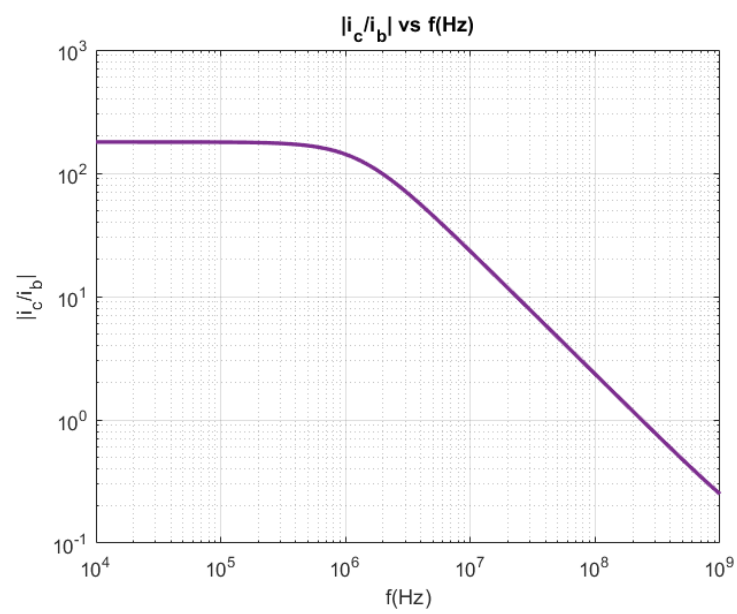

Figure 9. Current Gain Vs Unity Beta Frequency. [16].

And also the rise time analysis on $\mathrm{I}_{\mathrm{CC}} \tau_{\mathrm{t}} / \mathrm{I}_{\mathrm{BB}} \tau_{\mathrm{B}}$ is shown in Figure 10. According to this result, if the value of the ratio of $\mathrm{t}_{\mathrm{r}} / \tau_{\mathrm{B}}$ could be started from 0 to maximum of 5 based on the value of that ratio of $\mathrm{I}_{\mathrm{CC}} \tau_{\mathrm{t}} / \mathrm{I}_{\mathrm{BB}} \tau_{\mathrm{B}}$ gradually increase from 0 to 1 . That result could be accepted to design the HEBT structure based on one of the physical parameter for analysis.

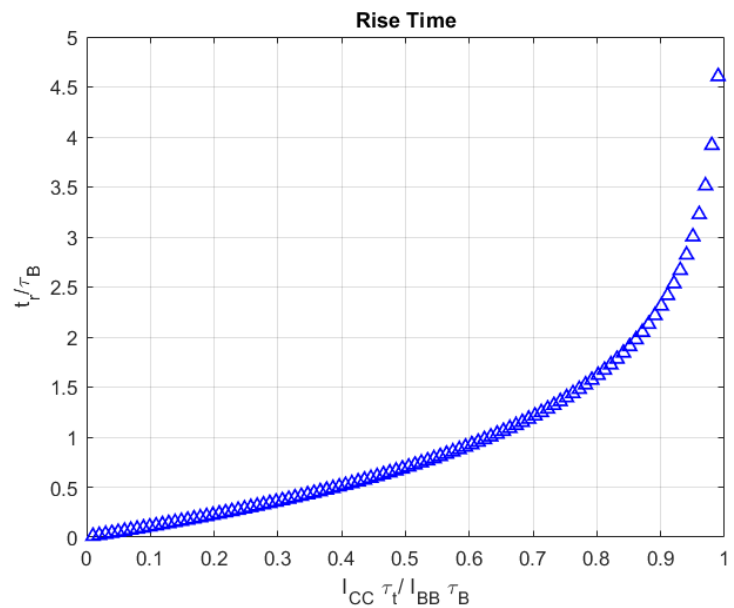

Figure 10. Rise Time. [16].

The storage delay time response for analyzing the performance of the HEBT structure is mentioned in Figure 11. In this figure, there have been two values of 0 and 1 for $\mathrm{x}_{\mathrm{i}}$ for storage delay time response analyses. According to this result, if the value of the ratio of $t_{\mathrm{sd}} / \tau_{\mathrm{B}}$ could be started from 0 to maximum of 5 based on the value of that ratio of $\mathrm{I}_{\mathrm{CC}} \tau_{\mathrm{t}} / \mathrm{I}_{\mathrm{BB}} \tau_{\mathrm{B}}$ gradually increase from 0 to 1 . The response for $x_{i}=0$ shows the ratio of $\mathrm{t}_{\mathrm{sd}} / \tau_{\mathrm{B}}$ could be observed the maximum value at the value of the ratio of $\mathrm{I}_{\mathrm{CC}} \tau_{\mathrm{t}} / \mathrm{I}_{\mathrm{BB}} \tau_{\mathrm{B}}$ was zero and it was decaying from the value of 5 to 0 . Similarly, the response for $\mathrm{x}_{\mathrm{i}}=1$ shows the ratio of $\mathrm{t}_{\mathrm{sd}} / \tau_{\mathrm{B}}$ could be observed the maximum value at the value of the ratio of $\mathrm{I}_{\mathrm{CC}} \tau_{\mathrm{t}} / \mathrm{I}_{\mathrm{BB}} \tau_{\mathrm{B}}$ was zero and it was decaying from the value of 0.6 to 0 . Therefore, the value of $x_{i}$ is very important and significant effects to design the high performance device fabrication. 


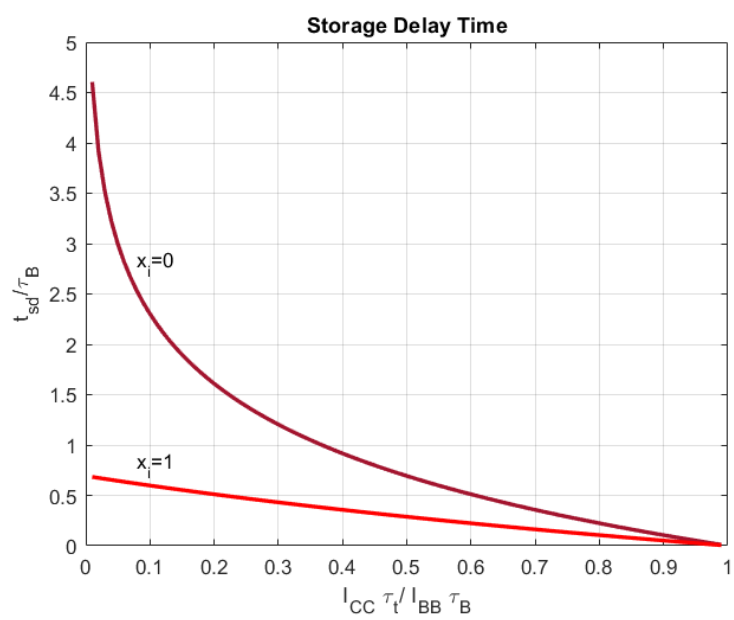

Figure 11. Storage Delay Time. [16].

The fall time response is also mentioned based on the ratio of $\mathrm{I}_{\mathrm{CC}} \tau_{\mathrm{t}} / \mathrm{I}_{\mathrm{BB}} \tau_{\mathrm{B}}$ and it is also demonstrated in Figure 12. The two conditions of $\mathrm{x}_{\mathrm{i}}=0$ and 1 for fall time analysis in this figure. For $\mathrm{x}_{\mathrm{i}}=0$ condition, the fall time values are constant at 2.2 of $\mathrm{t}_{\mathrm{T}} / \tau_{\mathrm{B}}$. For $\mathrm{x}_{\mathrm{i}}=1$ condition, the fall time values would be increase from 0 to 0.55 of $\mathrm{t}_{\mathrm{r}} / \tau_{\mathrm{B}}$.

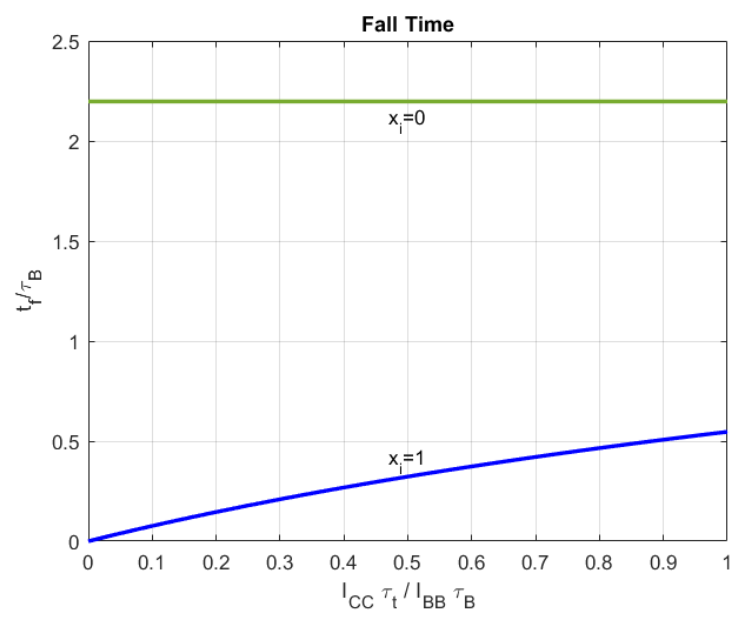

Figure 12. Fall Time. [16].

The electrical characteristics of developed HEBT design are based on various values of IB from $1 \mu \mathrm{A}$ to $4 \mu \mathrm{A}$. In these results, the phase change condition is considered. If there is no phase change for the value of IB, the results are acceptable. If the phase change of IB values, the results could not be acceptable. Figure 13 shows the Voltage-Current Characteristics of the developed HEBT structure.

The phonon effect on the Quantum Well-based HEBT Design is shown in Figure 14. In this calculation, the transmission spectrum is utilized based on polarization effects between different semiconductor materials.

The important consideration on developed quantum-well based HEBT structure is the comparison between conventional BJT and developed HEBT. Figure 15 illustrates the Comparison of Conventional Transistor Design and Developed Quantum Well-based HEBT Design.

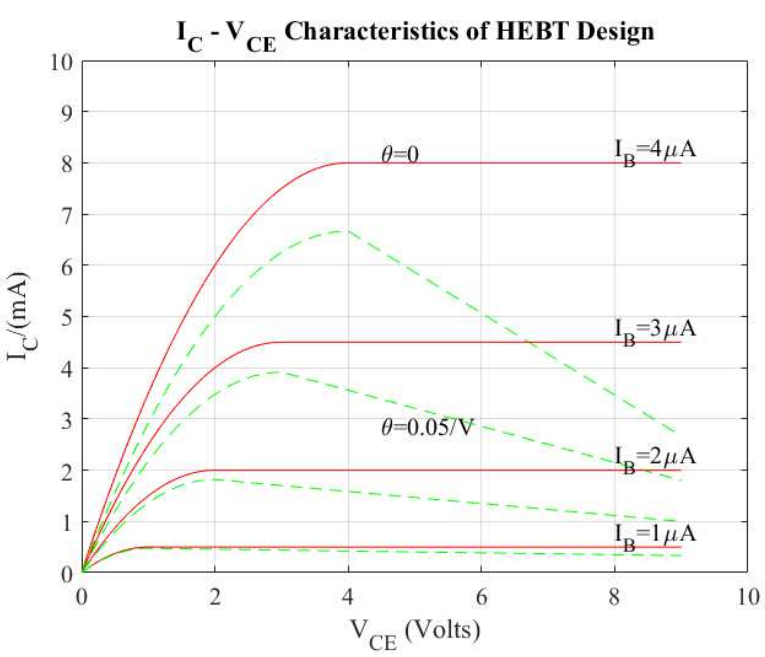

Figure 13. Voltage-Current Characteristics.

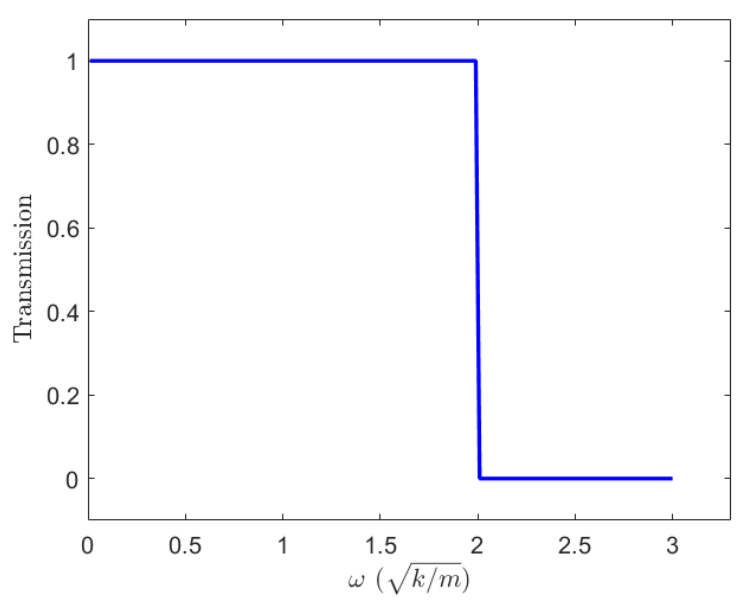

Figure 14. Phonon Effects on Quantum Well-based HEBT Design.

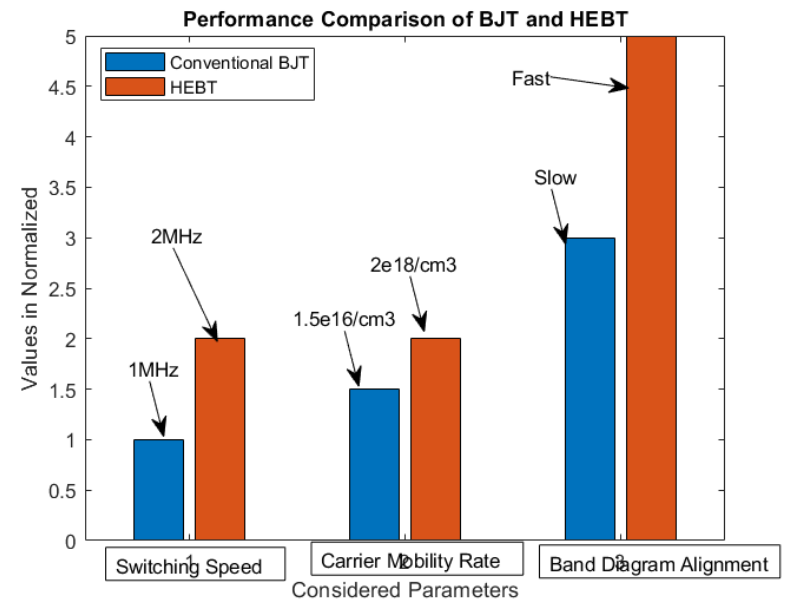

Figure 15. Comparison of Conventional Transistor Design and Developed Quantum Well-based HEBT Design.

We considered only on the switching speed, carrier mobility rate and band diagram alignment between two types of transistor structures. 


\section{Conclusion}

The Minority Carrier Distribution in the Base of a HEBT Variation with W/LB has been evaluated based on the physical parameters. The HEBT Biasing Mode Illustration for three operating regions of active, cut off and saturation with numerical analyses. The four ratios of $\mathrm{N}_{\mathrm{E}} / \mathrm{N}_{\mathrm{E} 0}, \mathrm{~N}_{\mathrm{B}} / \mathrm{N}_{\mathrm{B} 0}, \tau_{\mathrm{E}} / \tau_{\mathrm{E} 0}$ and $\tau_{\mathrm{B}} / \tau_{\mathrm{B} 0}$ is mentioned and checked based on the physical parameters for proposed HEBT. The actual results of IC and IB are also calculated based on VEB. Based on the numerical analyses on multi quantum-well HEBT structure, the physical characteristics of proposed transistor model were evaluated. The results on current gain, rise time, storage delay time and fall time responses are vital role to enhance the high performance of HEBT structure in reality. The performance comparison for BJT and HEBT was proved that the proposed HEBT belongs to high performance condition for device fabrication. The results confirmed that the proposed HEBT structure is appropriate for PNP configuration for high frequency applications.

\section{References}

[1] P. M. Asbeck, M.-C. F. Chang, J. A. Higgins, N. H. Sheng, G. J. Sullivan, and K.-C. Wang, IEEE Trans. Electron Devices 36, 2032 (1989).

[2] W. Hafez, W. Snodgrass, and M. Feng, Appl. Phys. Lett. 87, 252109 (2005)

[3] D. A. Ahmari, G. Raghavan, Q. J. Hartmann, M. L. Hattendorf, M. Feng, and G. E. Stillman, IEEE Trans. Electron Devices 46, 634 (1999).

[4] W. Liu, S.-K. Fan, T. Henderson, and D. Davito, IEEE Trans. Electron Devices 40, 1351 (1993).

[5] M. Feng, N. Holonyak, and W. Hafez, Appl. Phys. Lett. 84, 151 (2004).
[6] Sze S M 1981 Physics of Semiconductor Devices 2nd edn (New York: Wiley).

[7] Singh J 2000 Semiconductor Devices: Basic Principles 1st edn (New York: Wiley).

[8] Kasap S O 2006 Principles of Electronic Materials and Devices 3rd edn (New York: McGraw-Hill).

[9] Neamen A D 2003 Semiconductor Physics and Devices: Basic Principles 3rd edn (New York: McGraw-Hill).

[10] Rhoderick E H 1970 The physics of Schottky barriers J. Phys. D: Appl. Phys. 31153.

[11] Sharma B L 1984 Metal-Semiconductor Schottky Barrier Junctions and their Applications 1st edn (New York: Plenum).

[12] Son Y and Peterson R L 2017 The effects of localized tail states on charge transport mechanisms in amorphous zinc tin oxide Schottky diodes Semicond. Sci. Technol. 32 12LT02.

[13] Ohmi T, Saito T, Shibata T and Nitta T 1988 Room-temperature copper metallization for ultralarge-scale integrated circuits by a low kinetic-energy particle process Appl. Phys. Lett. 522236

[14] Raychaudhuri and Barun 1995 Some Studies on Electrical Characteristics of Metal Semiconductor Contacts with Thin Interfacial Insulating Layer PhD Thesis University of Calcutta.

[15] Hsu Myat Tin Swe, Hla Myo Tun "Multi-Quantum Well Design for Heterojunction Emitter Bipolar Transistors (HEBTs)" Published in International Journal of Trend in Research and Development (IJTRD), ISSN: 2394-9333, Volume-7 | Issue-1, February 2020, URL: http://www.ijtrd.com/papers/IJTRD 21950.pdf.

[16] Hsu Myat Tin Swe, Hla Myo Tun, Myint Myint Than, Maung Maung Latt, "Design of Quantum-Well Heterojunction Biploar Transistor Based on Physical Parameters, International Conference on Science, Technology, and Management (ICSTM), Singapore, $2^{\text {nd }}-3^{\text {rd }}$ April 2020. 